American Journal of Applied Sciences 5 (11): 1487-1493, 2008

ISSN 1553-345X

(C) 2008 Science Publications

\title{
Traffic Signal Using Smart Agent System
}

\author{
${ }^{1}$ Cheonshik Kim, ${ }^{2}$ You-Sik Hong \\ ${ }^{1}$ Anyang University, Faculty of Major in Digital Media Engineering, \\ Anyang-si, Gyeonggi-do, South Korea \\ ${ }^{2}$ Sangji University, Faculty of Computer Science, Usan-dong, Wonju-si, South Korea
}

\begin{abstract}
In this research, we propose an electro-sensitive traffic light using the smart agent algorithm to reduce traffic congestion and traffic accidents. The multi-agent system approach can provide a new and preferable solution. The proposed method adaptively controls the cycle of traffic signals even though the traffic volume varies. Consequently, we reduce the car waiting time and start-up delay time using fuzzy control of feedback data. In particular, we have designed and implemented a system to create optimum traffic signals in congested conditions. The effectiveness of this method was shown through simulation of multiple intersections.
\end{abstract}

Key words: Traffic signal, smart agent, car, accident

\section{INTRODUCTION}

Most urban areas nowadays experience severe traffic jams on street networks. As the traffic congestion spreads, there is a need to apply intelligent algorithms to diminish the waste of time, air pollution, and so on. Therefore, a traffic control system seeks to minimize the delay experienced by vehicle travelling through a road network of intersections by manipulating the traffic signal plans. There are various levels of sophistication in traffic signal control system using fuzzy traffic control. Agent-oriented fuzzy traffic control is a useful tool in designing traffic signal timing plans adaptively ${ }^{[1]}$.

In fact, agent technology was begun in the 1950s. Agent is a software that user achieves automatically wanting work. In particular, this is a concept that has been studied for a long time in artificial intelligence. From the late 1980s, a boundary that is an agent has been detached with artificial intelligence and exposed to individual study subject. Agent products have appeared since the early $1990 \mathrm{~s}^{[2]}$. A multi-agent system consists of multiple agents who are autonomous and make their decisions independently. By this definition, we rule out those systems where a central planner or designer controls the decision processes of local agents. If the agents' actions do not affect each others' outcomes, then we may as well consider the agents' situations independently ${ }^{[3]}$. A multi-agent system offer certain advantages for problem solving: faster response, increased flexibility, robustness, resource sharing, and better adaptability ${ }^{[4,5]}$.

Traffic signal control is also one of these applications ${ }^{[6,7]}$. A lot of technical research ${ }^{[8,9,10,11]}$ present fuzzy systems for a multi-way single intersection. In spite of traffic signal using fuzzy system, the control problem for network intersections still is an important issue in the field of traffic engineering ${ }^{[12]}$. Fuzzy logic is derived from fuzzy set theory dealing with reasoning that is approximate rather than precisely deduced from classical predicate logic. It can be thought of as the application side of fuzzy set theory dealing with well thought out real world expert values for a complex problem ${ }^{[14]}$. In 1990's, application of this method are widely used all over the world.

The FLC (fuzzy logic control) uses three linguistic input variables and one linguistic output. The fuzzy input variables are the passed time of the current interval, the number of vehicles crossing an intersection during the green phase, and the length of queuing from the red direction. The extension time calculated using 27 fuzzy rules is the output. This FLC was simulated at less critical intersections. Gomide et al. proposed a FLC with adaptive strategies for fuzzy urban traffic systems $^{[13]}$. The FLC adjusts the membership functions according to the traffic conditions to optimize the controller's performance.

Traffic signals are not a cure-all for every problem intersection. In Korea, traffic congestion is very much so that wrong traffic control signal is one of cause.

Corresponding Author: Cheonshik Kim, Anyang University, Faculty of Major in Digital Media Engineering, Anyangsi Manan-gu Anyang 5(o)-dong Anyang Univ.,Gyeonggi-do,430-714, South Korea

Tel: +82-2-463-1387, Fax: +82-2-467-0789 
Since drive time is a non-productive activity, congestion reduces regional economic health by increasing drive times. Traffic congestion's cause is traffic incident. Traffic incidents are events that disrupt the normal flow of traffic, usually by physical impedance in the travel lanes. Events such as vehicular crashes, breakdowns, and debris in travel lanes are the most common form of incidents. With increasing numbers of vehicles on restricted roads, it happens that we have much wasted time and decreased average car speed.

Therefore, in this research, we will analyze traffic circumstance by real-time and solve traffic congestion using smart agent system. In addition, this research proposes a new concept of coordinating green time, which controls 10 traffic intersection systems.

\section{MATERIALS AND METHODS}

Let us suppose that we have the best traffic control signal, but it cannot produce the most suitable green time in case of a sudden increase in traffic volume such as created by a traffic accident or by street construction work. In particular, let us suppose that the increase exceeds the capacity of the intersection beyond $100 \%$. Then road conditions occur that fills an intersection with vehicles and creates a blocked phenomenon. As a result, roads become a parking lot and the traffic control signal functions badly in these circumstances. Such a problem is very difficult to correct in creating a traffic cycle. Therefore, we suggest new traffic signal concept that can control 10 intersections.

We defined fuzzy rule base for traffic congestion circumstance and described calculation method. The traffic volume balance is held at each signalized intersection of the traffic network for a certain sampling period. It can be described by the following Eq.

where,

$$
\mathrm{C}_{\mathrm{e}}(\text { green })=\mathrm{G}_{\mathrm{rte}}(\mathrm{car})+\mathrm{G}_{\mathrm{rit}}(\mathrm{car})-\mathrm{G}_{\mathrm{rto}}(\mathrm{car})
$$

$\mathrm{G}_{\mathrm{rte}}(\mathrm{car})=$ Excess incoming traffic cars

$\mathrm{G}_{\mathrm{rti}}(\mathrm{car})=$ Incoming traffic cars

$\mathrm{G}_{\mathrm{rto}}(\mathrm{car})=$ Outgoing traffic cars

If there are so many vehicles in the line, we cannot know how many vehicles go to straight or right turn. Therefore to determine optimal green time, it must predict the number of straight turn not a turn right.

$$
\begin{aligned}
& \mathrm{C}_{\mathrm{e}} \text { (green) }=\mathrm{C}_{\mathrm{xe}}(\mathrm{in}) * \mathrm{R}_{\mathrm{tn}}(\text { exp_in })+\mathrm{S}_{\mathrm{tr}}(\text { exp_in }) \\
& \left.\mathrm{C}_{\mathrm{rt}}(\text { green })=\mathrm{N}_{1} * \mathrm{~W}_{\mathrm{L}} * \mathrm{C}_{\mathrm{xl}} \text { (in, out }\right)
\end{aligned}
$$

where :

Cxe(in) = Excess incoming traffic cars

Rtn $($ exp_in $)=$ Expected cars for right turn

Str(exp_in) $=$ Expected cars for straight

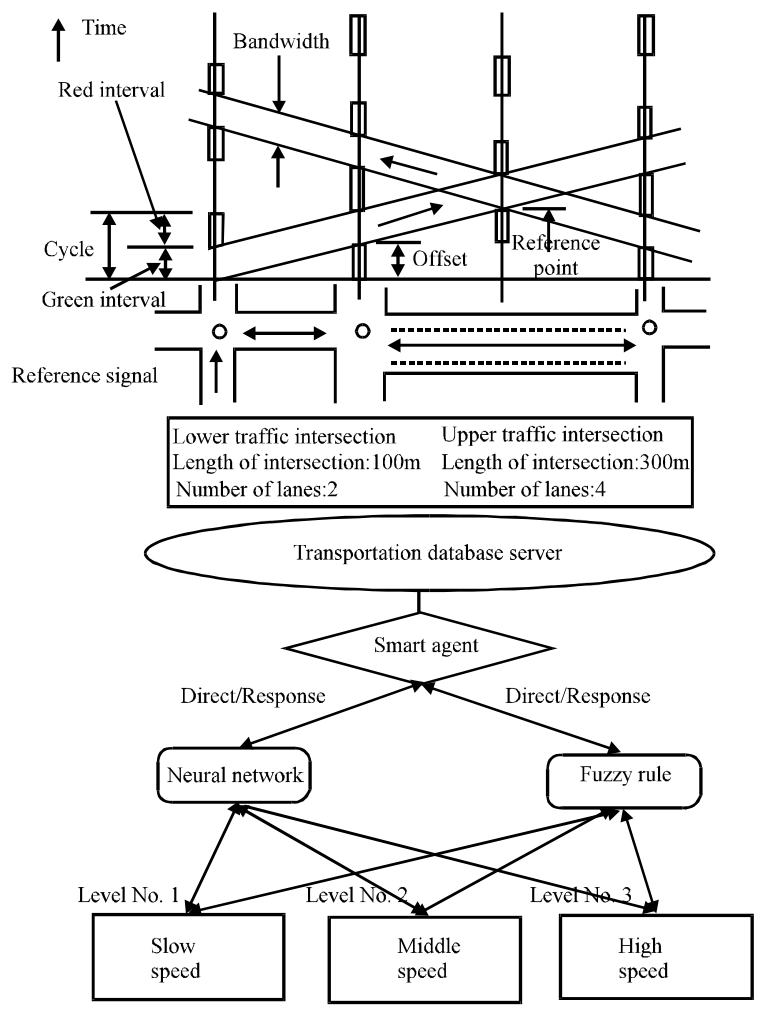

Fig. 1: Architectural view of proposed agent-oriented traffic simulation system

Figure 1 explains how to create optimal green time, offset, red interval and waiting queue depending on different length of lower and upper traffic intersection.

Fuzzy traffic control simulator was developed by agent-oriented paradigm. We implemented the simulator suitable for traffic junction networks in Visual $\mathrm{C}++$ to analyze traffic conditions and to calculate the optimized traffic signals. Agent-oriented programming allows the simulation to be built in a modular fashion making it easily expandable and maintainable. As an example of agent-oriented programming by using MFC, if you make a new control algorithm and put it into the crossroad agent, the algorithm works well.

Figure 2 shows the overall architecture of each single intersection. The variety of agent such as fuzzy rules, neural networks, adaptive fuzzy, fog road, ice road and sharp curve are responsible for perceiving cars and road.

Figure 3 shows the structure of an efficient intelligent traffic system which is used for a smart car in a complex intersection. According to intersection lane and intersection length, the numbers of passing vehicles differ during the green cycle time. Until now, a 
Am. J. Applied. Sci., 5 (11): 1487-1493, 2008

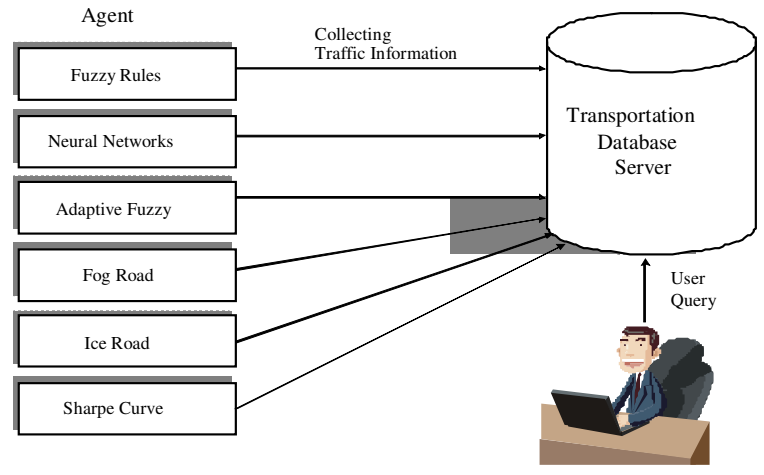

Fig. 2: The overall architecture of smart agent

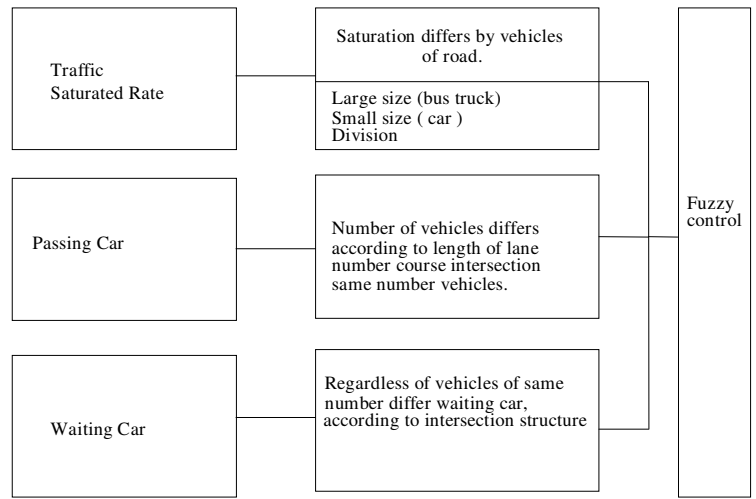

Fig. 3: Structure of intelligent traffic system

traffic control signal of 10 minutes was not considered for a current traffic signal in these conditions. As a result, the traffic signal cycle was incorrect more than 30 to $45 \%$ during rush $\mathrm{h}$. Therefore, we used the fuzzy rule to correct this problem. As a result, we propose an efficient traffic signal algorithm to improve the previous traffic signal algorithm and minimise car latency time in rush hour traffic.

Table 1 shown 3 kinds of traffic saturation degree. In the case of many traffic jams on the roads, the best traffic signal algorithm could not solve the problem of traffic jams in any case. Therefore, to improve car latency time and average running, we need to improve the stream of traffic. So we give priority to the assumption that there is a lot of traffic. That is, we give an offset value to the traffic formula and get good traffic signal cycles.

\section{RESULTS AND DISCUSSION}

In this research, we take advantage of an intelligence style agent technique to solve many traffic jams problems. That is, we use 3 cycles of passing
Table 1: Three Kinds of traffic saturation degree

\begin{tabular}{|c|c|}
\hline Degree of Low Saturation & $\begin{array}{l}\text { High intersection, Low Intersection, } \\
\text { states that do not become waiting lines }\end{array}$ \\
\hline \multicolumn{2}{|c|}{ Degree of Middle Saturation } \\
\hline Comfortable state & $\begin{array}{l}\text { Queuing does not form at high } \\
\text { intersection, and waiting lines } \\
\text { diminish to low intersection or } \\
\text { saturation } 0.5 \text { preservation }\end{array}$ \\
\hline Uncomfortable state & $\begin{array}{l}\text { Queuing does not form at high } \\
\text { intersection, and waiting lines grow } \\
\text { continuously to low intersection }\end{array}$ \\
\hline Degree of High Saturation & $\begin{array}{l}\text { Waiting lines are created at high } \\
\text { intersection, and saturation is near to } 1 \\
\text { to low intersection and start-up } \\
\text { delays occur }\end{array}$ \\
\hline
\end{tabular}

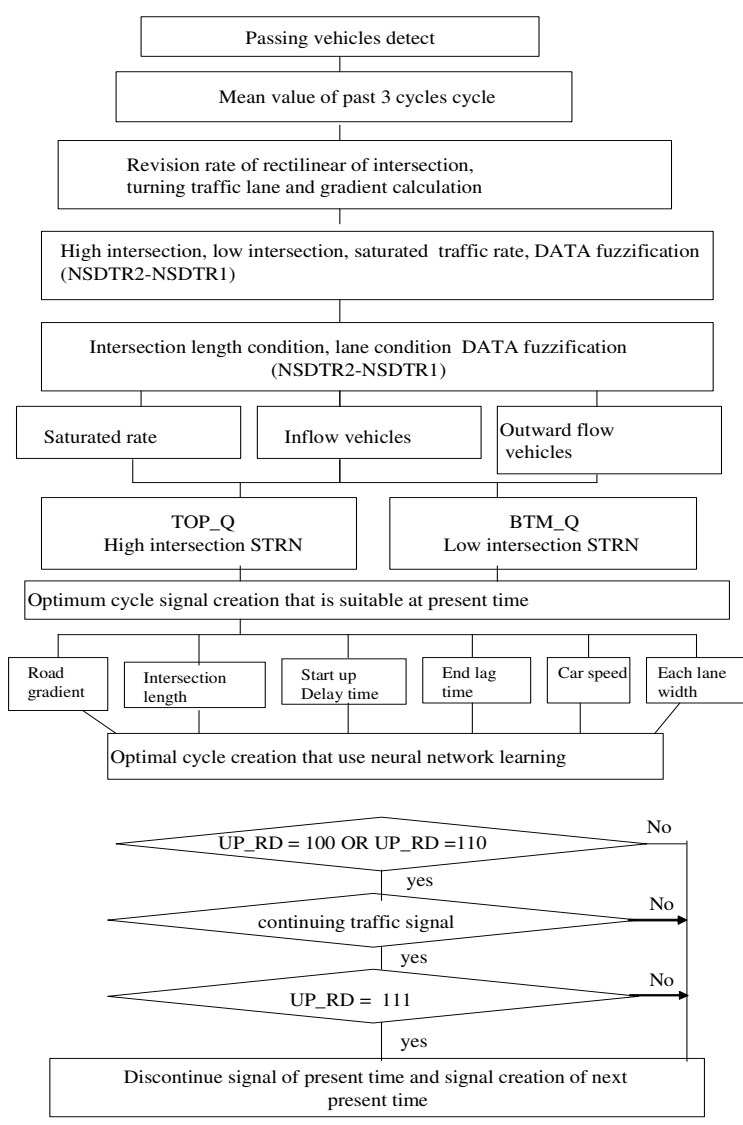

Fig. 4: Agent traffic signal using intelligent

vehicles, intersection lane condition, and intersection length condition value by the initial value of a neural network algorithm. Networks can propagate information in one direction only, or they can bounce back and forth until self-activation at a node occurs and the network settles on a final state. As a result, we get good traffic signal cycles using the proposed method of neural network algorithm. Figure 4 is a flowchart that explains the intelligent agent traffic signal. This 


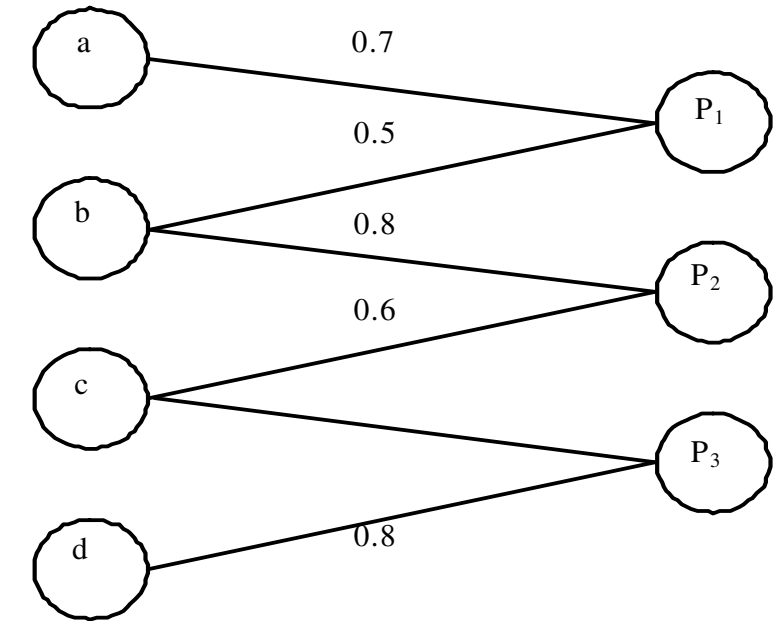

Fig. 5: Fuzzy conversion factor considering whether conditions

flowchart explains the traffic signal algorithm that we are proposing in Table 1. We described algorithms and calculation methods to supply optimal green time signal.

Figure 5 shows for a, b, c, and d each different road conditions. First the numbers $0.8 \sim 1.0$ implicate a heavy rainy road or frozen road, a regular raining road can be expressed by $0.5 \sim 0.7$. At least regular weather can be indicated by $0.1 \sim 0.4$. Hereby, as explained in Fig. 3, P1, P2, P3 explains the road incline considering whether conditions. The connection lines represent the vehicle type. Therefore even the heavy raining road condition may be same, the road incline and vehicle type, in case of a large vehicle (0.8), regular (0.6) the final braking distance will be calculated under the assumption of the vehicle condition.

The neural network consists of one input layer, one hidden layer, and one output layer. We use supervised learning process, which adjusts weights to reduce the error between desired output and real output for green time. This is depicted as follows.

(1) Initialize weights and offset

(2) Establishment of training pattern

(3) Compute the error between target pattern output layer neural cell $\left(t_{j}\right)$ and output layer neural cell $\left(a_{j}\right)$

$$
e_{j}=t_{j}-a_{j}
$$

(4) Calculate weights between input neural cell( $(i, j)$ by the following equation

$$
\mathrm{W}(\text { new })_{\mathrm{ij}}=\mathrm{W}(\mathrm{old})_{\mathrm{ij}}+\mathrm{ae}_{\mathrm{iaj}}
$$

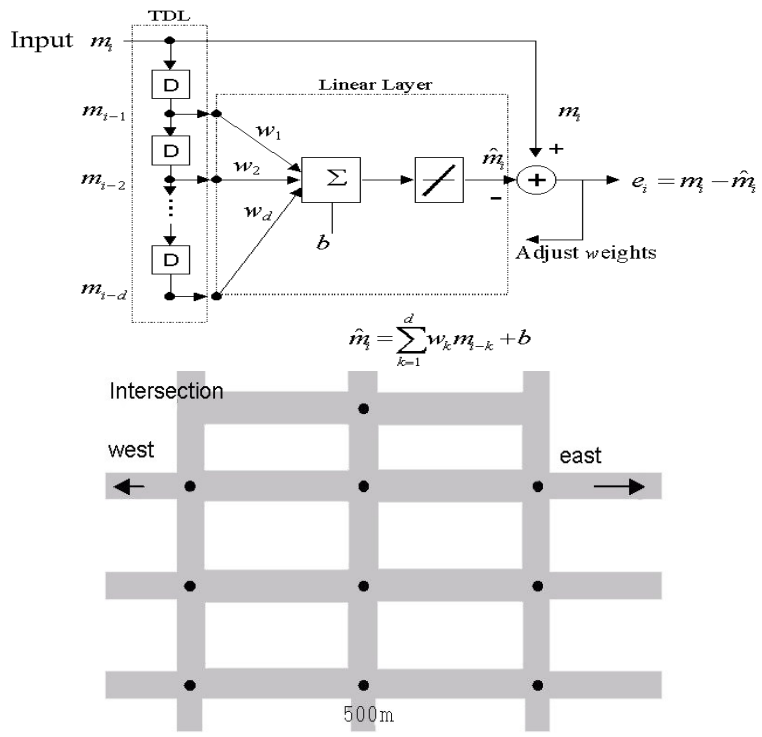

Fig. 6: Optimal traffic cycle of 10 traffic intersections

$$
\mathrm{e}_{\mathrm{j}}=\mathrm{t}_{\mathrm{j}}-\mathrm{a}_{\mathrm{j}}
$$

(5) Repeat the process from number (2) above.

The process is repeated until optimal green time is calculated. In order to create optimal green time, it must consider different can lengths, length of traffic intersection and width of traffic intersection. If there are same waiting vehicle in the traffic intersection, we cannot estimate offset and conversion factor of different traffic intersection. Therefore, we need adaptive fuzzy neural traffic control.

Figure 6 shows explain how to create offset and optimal green time of different 20 traffic conditions. Therefore, we need adaptive fuzzy neural traffic control.

Figure 7 shows explain how to create offset and optimal green time of different 20 traffic conditions.

This smart agent algorithm for optimal green time accomplishes this:

- First decide 10 different intersections into 3 by 3 amounts and analyze traffic level, accumulated number of vehicles waiting.

- In order to analyze the current passing traffic creating the minimum period of green signal by calculating check-in direction 1 traffic and traffic of checkout direction 2 is necessary.

- If the higher and lower detectors of the intersection are both reading "on," and the accumulated number of vehicles is on "high," the intersection is overloaded with cars. 


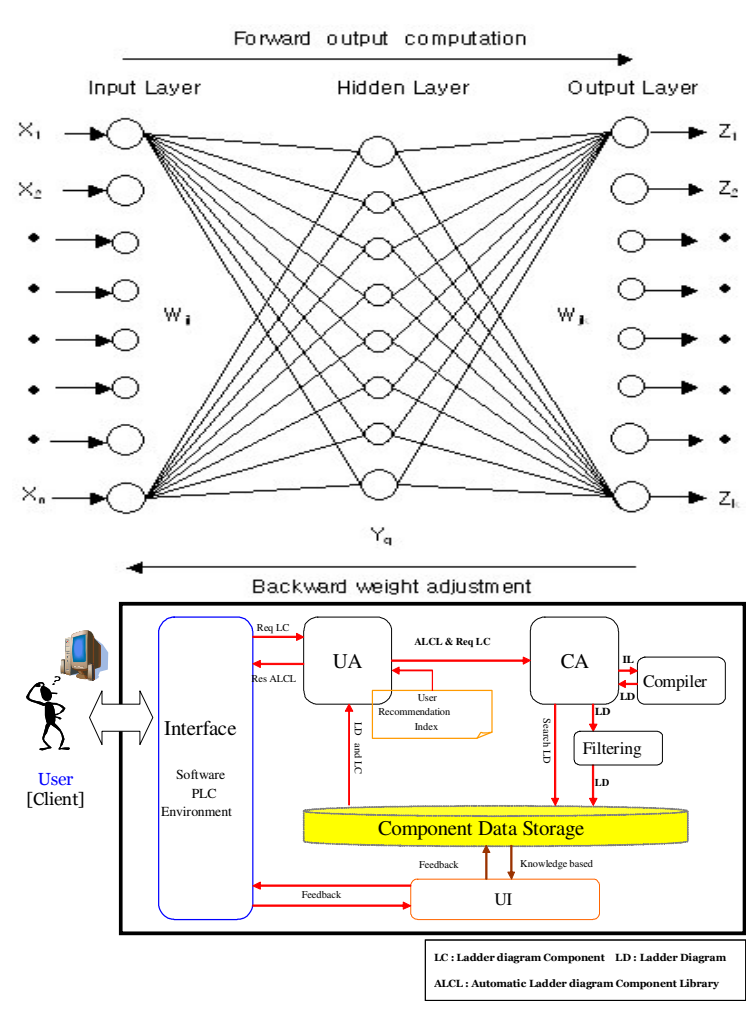

Fig. 7: Simulation of fuzzy-neural traffic light

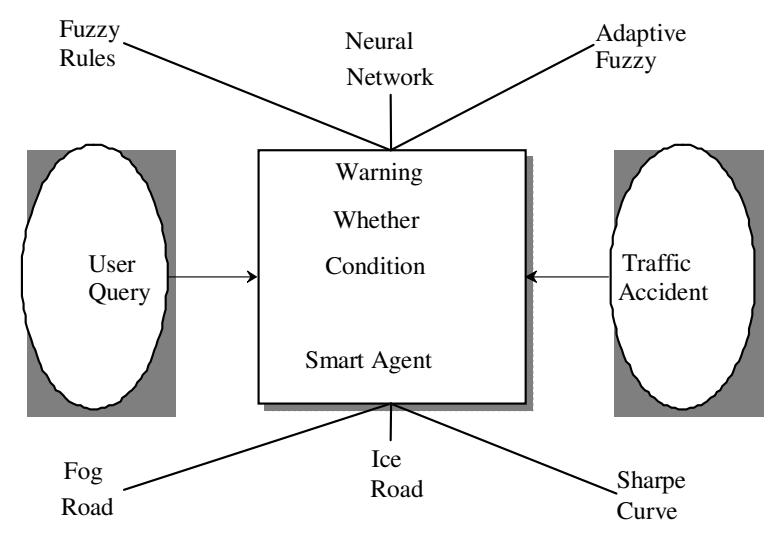

Fig. 8: Forecasting traffic situation using smart agent

- Calculate the minimum period of green signal by using predicted traffic amount operation and predicted passing time.

Figure 8 is shown composition of sensor database. This system collects traffic circumstance at real-time. And, collected information is stored to database. Also, stored information is used to forecast the future.

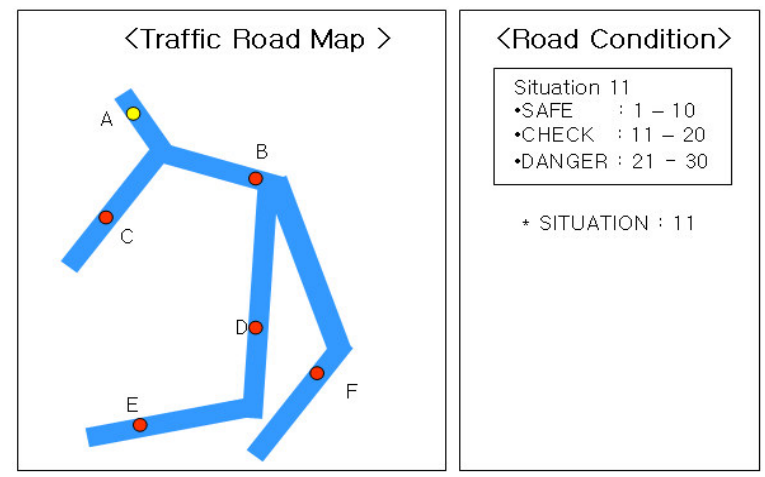

Fig. 9: Simulation for smart agent

Table 2: Simulation result using smart agent

\begin{tabular}{|c|c|c|c|c|c|c|c|c|c|}
\hline \multirow{2}{*}{$\begin{array}{l}\text { Traffic } \\
\text { Road } \\
\text { Road I.D. }\end{array}$} & \multicolumn{4}{|c|}{ Whether conditions } & \multicolumn{3}{|c|}{ Speed conditions } & \multicolumn{2}{|c|}{ Smart agent } \\
\hline & Rain & Sun & Snow & Fog & LV1 & LV2 & LV3 & Danger & Normal \\
\hline $\mathrm{ABC}$ & 44 & 100 & 34 & 70 & 83 & 17 & 21 & $\mathrm{O}$ & $\mathrm{X}$ \\
\hline $\mathrm{CDE}$ & 84 & 88 & 66 & 50 & 16 & 24 & 81 & $\mathrm{O}$ & $\mathrm{X}$ \\
\hline $\mathrm{ABC}$ & 64 & 100 & 23 & 46 & 91 & 30 & 10 & $\mathrm{O}$ & $\mathrm{X}$ \\
\hline EFG & 86 & 91 & 56 & 23 & 12 & 88 & 14 & $X$ & $\mathrm{O}$ \\
\hline $\mathrm{ABC}$ & 94 & 100 & 34 & 78 & 21 & 31 & 87 & $\mathrm{X}$ & $\mathrm{O}$ \\
\hline $\mathrm{CDE}$ & 82 & 97 & 45 & 56 & 13 & 92 & 17 & $\mathrm{O}$ & $\mathrm{X}$ \\
\hline $\mathrm{ABC}$ & 74 & 88 & 58 & 55 & 18 & 24 & 91 & $\mathrm{X}$ & $\mathrm{O}$ \\
\hline
\end{tabular}

Figure 9 shows that while vehicles drive, when accident occurs or an obstacle is finding. At that time, it will tell the traffic situation to the driver using smart agent.

In this research, it can automatically calculate an optimal green time and speed level when it finds an obstacle, traffic accident and weather conditions using smart agent algorithm. Table 2 shows simulation result using smart agent.

We propose using a sensor network to solve the smart traffic signal in a complex intersection. Each node in a sensor network is typically equipped with a radio transceiver or other wireless communications device, a small microcontroller, and an energy source, usually a battery. A wireless sensor network (WSN) is a wireless network consisting of spatially distributed autonomous devices using sensors to monitor physical or environmental conditions cooperatively, such as temperature, sound, vibration, pressure, motion or pollutants, at different locations.

Figure 10 shows that sensor nodes collect traffic information using the fuzzy method and users query the agent system for traffic information. As a result, users can get optimal traffic information from the agent system.

The method that we propose reduces the traffic signal cycle in the case that passing vehicles are more than $90 \%$ of the capacity of the intersection. In 


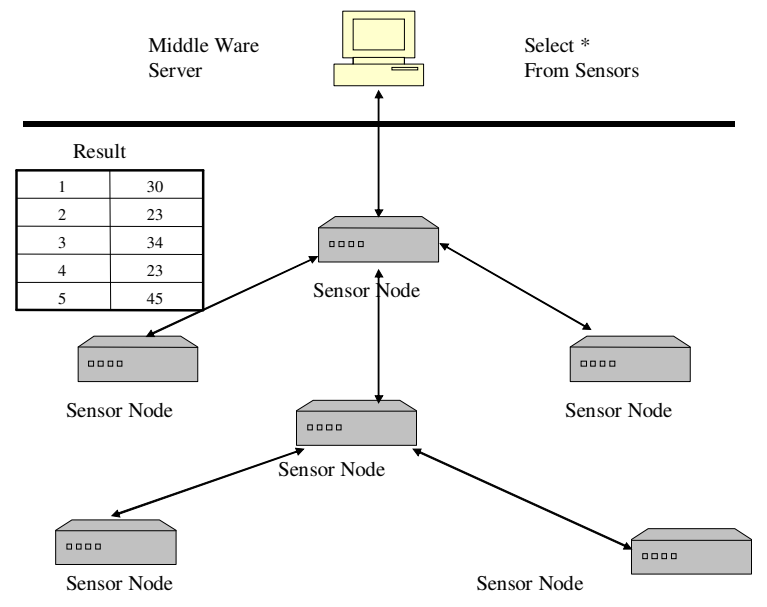

Fig. 10: Collect traffic information using WSN

particular, if a traffic accident or various road work or other events happen, the proposed algorithm operates 2 phases for car latency time. This information is used by the fuzzy rule for degrees of middle saturation, high saturation and low saturation in Table 3.

We explain situations that input 10 different conditions to predict traffic intersection cycles. In this research, we use 10 different conditions, which are passing car during 3cycles, outward car and length of intersection. These input values of conditions are used for learning in the neural network. As a result, the proposed system predicts an efficient smart agent algorithm.

\section{CONCLUSION}

We have introduced the traffic volume parameter into the smart agent algorithm to improve the performance of the FLC suitable for urban crossroads with time-varying flow rates. In this research, we have implemented an agent-oriented multiple crossroad simulator with $\mathrm{n} \times \mathrm{n}$ intersections to evaluate the performance of the traffic signal control algorithms.

We utilized an agent-oriented paradigm to extend or maintain the developed system easily. Since our real traffic situation is suitable for design agents on urban road networks, we chose an agent-oriented scheme to develop the traffic simulator. The developed simulator can be tested in specific traffic situations by changing input parameters such as traffic volume set. The proposed FLC has been applied to crossroads with various traffic flow rates.

The simulation results indicate that the proposed FLC yields lower average delay and lower average cost than conventional controllers. This verifies that the proposed method fits the real needs at traffic junctions. Further research is needed to develop a more coordinated approach to solve cooperation and negotiation between neighbouring traffic junctions. Also, in protecting the spillback phenomenon of multiple crossroads, we have to consider car size, such as small automobile and large car, bus or trailer.

In this research, it proposed that we establish a safe priority order using fuzzy rules. Moreover, to prevent traffic congestion, this approach can adapt the control itself when sensing upper traffic intersection and different saturation rate, road length, road slopes and road width, and we can create optimal green time using the smart agent algorithm. It will be able to forecast the optimal traffic information, estimation of destination arrival time, roads under construction and dangerous roads, using the smart agent algorithm. With computer simulation, we prove that the traffic congestion phenomenon generated under highly saturated traffic conditions is improved by using smart agent algorithm.

Table 3: Suitable cycle using the neural net work of agent method

\begin{tabular}{|c|c|c|c|c|c|c|c|}
\hline \multirow{2}{*}{$\begin{array}{l}\text { Intersection I.D. } \\
\text { Traffic Accident } \\
\text { (yes or no) }\end{array}$} & \multicolumn{6}{|c|}{ Input pattern Target } & \multirow[b]{2}{*}{$\begin{array}{l}\text { Target } \\
\text { pattern }\end{array}$} \\
\hline & \multicolumn{2}{|l|}{ Low saturation } & \multicolumn{2}{|c|}{ Middle saturation } & \multicolumn{2}{|c|}{ High saturation } & \\
\hline \multirow[t]{4}{*}{0} & $\begin{array}{l}\text { Intersection } \\
\text { length }\end{array}$ & $\begin{array}{l}\text { No. of } \\
\text { lane }\end{array}$ & $\begin{array}{l}\text { Length of } \\
\text { intesection }\end{array}$ & $\begin{array}{l}\text { No. of } \\
\text { lane }\end{array}$ & $\begin{array}{l}\text { Length of } \\
\text { intersection }\end{array}$ & $\begin{array}{l}\text { No. of } \\
\text { lane }\end{array}$ & \\
\hline & $\mathrm{L} 1>\mathrm{L} 2$ & $\mathrm{~W} 1>\mathrm{W} 2$ & $\mathrm{~W} 1>\mathrm{W} 2$ & $\mathrm{~W} 1>\mathrm{W} 2$ & $\mathrm{~W} 1>\mathrm{W} 2$ & $\mathrm{~W} 1>\mathrm{W} 2$ & Q1 \\
\hline & & $\mathrm{W} 1=\mathrm{W} 2$ & $\mathrm{~W} 1=\mathrm{W} 2$ & $\mathrm{~W} 1=\mathrm{W} 2$ & $\mathrm{~W} 1=\mathrm{W} 2$ & $\mathrm{~W} 1=\mathrm{W} 2$ & Q2 \\
\hline & & $\mathrm{W} 1<\mathrm{W} 2$ & $\mathrm{~W} 1<\mathrm{W} 2$ & $\mathrm{~W} 1<\mathrm{W} 2$ & $\mathrm{~W} 1<\mathrm{W} 2$ & $\mathrm{~W} 1<\mathrm{W} 2$ & Q3 \\
\hline \multirow[t]{3}{*}{0} & $\mathrm{~L} 1=\mathrm{L} 2$ & $\mathrm{~W} 1>\mathrm{W} 2$ & $\mathrm{~W} 1>\mathrm{W} 2$ & $\mathrm{~W} 1>\mathrm{W} 2$ & $\mathrm{~W} 1>\mathrm{W} 2$ & $\mathrm{~W} 1>\mathrm{W} 2$ & Q4 \\
\hline & & $\mathrm{W} 1=\mathrm{W} 2$ & $\mathrm{~W} 1=\mathrm{W} 2$ & $\mathrm{~W} 1=\mathrm{W} 2$ & $\mathrm{~W} 1=\mathrm{W} 2$ & $\mathrm{~W} 1=\mathrm{W} 2$ & Q5 \\
\hline & & $\mathrm{W} 1<\mathrm{W} 2$ & $\mathrm{~W} 1<\mathrm{W} 2$ & $\mathrm{~W} 1<\mathrm{W} 2$ & $\mathrm{~W} 1<\mathrm{W} 2$ & $\mathrm{~W} 1<\mathrm{W} 2$ & Q6 \\
\hline \multirow[t]{3}{*}{0} & $\mathrm{~L} 1<\mathrm{L} 2$ & W1>W2 & W1>W2 & $\mathrm{W} 1>\mathrm{W} 2$ & $\mathrm{~W} 1>\mathrm{W} 2$ & W1>W2 & Q7 \\
\hline & & $\mathrm{W} 1=\mathrm{W} 2$ & $\mathrm{~W} 1=\mathrm{W} 2$ & $\mathrm{~W} 1=\mathrm{W} 2$ & $\mathrm{~W} 1=\mathrm{W} 2$ & $\mathrm{~W} 1=\mathrm{W} 2$ & Q8 \\
\hline & & $\mathrm{W} 1<\mathrm{W} 2$ & $\mathrm{~W} 1<\mathrm{W} 2$ & $\mathrm{~W} 1<\mathrm{W} 2$ & $\mathrm{~W} 1<\mathrm{W} 2$ & $\mathrm{~W} 1<\mathrm{W} 2$ & Q9 \\
\hline 1 & Don't care & Don't care & Don't care & Don't care & Don't care & Don't care & Q10 \\
\hline
\end{tabular}




\section{ACKNOWLEDGEMENTS}

This research was supported by the ministry of Construction and Transportation funded by the Korean Government. (Project No: 05- Base -B02)

\section{REFERENCES}

1. Iisakki Kosonen, 2003. Multi-agent fuzzy signal control based on real-time simulation. Transport. Res. Part C: Emerg. Technol., 11 5: 389-403.

2. Barbara Hayes-Roth, 1994. Integrating real-time AI techniques in adaptive intelligent agents. Annu. Rev. Automatic Programmin, 19: 1-11.

3. Junling $\mathrm{Hu}$ and Michael P. Weliman, 2001. Learning about other agents in a dynamic multiagent system. Cognitive Syst. Res., 2 (1): 67-79.

4. Findler, N. and G. Elder, 1995. Multiagent coordination and cooperation in a distributed dynamic environment with limited resources. Artificial Intel. Eng.,9: 229-238.

5. Rodriquez, J., P. Noriega, C. Sierra and J. Padget, 1997. FM96.5 a java-based electronic auction house. Proceeding of the 2nd International Conference on the Practical Application of Intelligent Agents and Multi-Agent Technology.

6. Nakatsuyama, M., H. Nagahashi and N. Nishizuka, 1984. Fuzzy logic phase controller for traffic junctions in the one-way arterial road. IFAC-World Congress, preprints, Budapest, pp: 13-18.
7. Tzes, A., W.R. McShane and S. Kim, 1995. Expert fuzzy logic traffic signal control for transportation networks. Institute of Transportation Engineer 65th Annual Meeting, Denver USA. pp: 154-158.

8. Niittymaki, Jarkko, P., 1997. Isolated traffic signals-vehicle dynamics and fuzzy control. Ph.D Thesis, Helsinki University of Technology, Civil and Environmental Engineering.

9. Favilla, J., A. Machion and F. Gomide, 1993. Fuzzy traffic control: Adaptive strategies. $2^{\text {nd }}$ IEEE International Conference on Fuzzy Systems, San Francisco, CA, 506-511.

10. Hoyer, R. and U. Jumar, 1994. Fuzzy control of traffic lights. $3^{\text {rd }}$ IEEE International Conference on Fuzzy Systems, Orlando, FL, 1526-1531.

11. Kelsey, R., K. Bisset and M. Jamshidi, 1993. A simulation environment of fuzzy control of traffic systems. 12 IFAC-World Congress, Sydney, Australia, 553-556.

12. Skowronski, W. and L. Shaw, 1993. Self-learning fuzzy traffic controller for a traffic junction. I. European Congress on Intelligent Techniques and Soft Computing-EUFIT 93, Aachen, Germany, 751-761.

13. Nakamiti, G. and F. Gomide, 1994. An evolutive fuzzy mechanism based on past experiences. $2^{\text {nd }}$ European Congress on Intelligent Techniques and Soft Computing-EUFIT 94, Aachen, Germany, 1211-1217.

14. Klir, George J., St Clair, Ute H., Yuan, Bo, 1997. Fuzzy Set Theory: Foundations and Applications. Englewood Cliffs, NJ: Prentice Hall. 